\title{
Teacher Education and Didactics Knowledge to Teach Statistics: A Case Study
}

\author{
Bruna Mayara Batista Rodrigues ${ }^{1 *}$ (D), João Pedro da Ponte ${ }^{1}$ (D) \\ ${ }^{1}$ Institute of Education-University of Lisbon, PORTUGAL \\ * Corresponding author: brunaa-rodrigues@hotmail.com
}

Received: 15 Dec. $2021 \bullet$ Accepted: 5 Feb. 2022

Citation: Rodrigues, B. M. B., \& da Ponte, J. P. (2022). Teacher Education and Didactics Knowledge to Teach Statistics: A Case Study. European Journal of Science and Mathematics Education, 10(2), 225-242. https://doi.org/10.30935/scimath/11717

\begin{abstract}
:
This article discusses how two beginning mathematics teachers mobilize and develop their didactics knowledge, specifically concerning knowledge of statistical content and teaching practice, during a teacher education experience. This work was developed as part of a specialization course for elementary school mathematics teachers, in the subjects Data Analysis I and II. The teacher education course took place in the West Zone of Rio de Janeiro, Brazil. This is a qualitative study with an interpretive paradigm, based on a case study with two beginning teachers. The data collected was obtained from sessions by a logbook, audio recordings, and interviews with the teachers after the teacher education course. The course was structured to articulate didactics and statistics knowledge from activities directed to teaching practice. Concerning statistical knowledge, the results show the development of knowledge about different concepts associated with carrying out statistical investigations. Regarding teaching practice, teacher's learning is highlighted to carry out statistical activities of exploratory nature and statistical investigations in the school context.

Keywords: didactics knowledge, teacher education, statistical education, case study
\end{abstract}

\section{INTRODUCTION}

According to the Pre-K-12 Guidelines for Assessment and Instruction in Statistics Education (GAISE) II (Bargagliotti et al., 2020), it is increasingly important to discuss statistical literacy, whose development is the ultimate goal of teaching statistics in basic education. The recent update of the GAISE report (Franklin et al., 2005) states that different global problems, such as changing climate conditions and the COVID-19 global pandemic, have reinforced the need for interpreting statistical information. Given this scenario, it is essential to highlight the responsibility of teachers in the statistical literacy of students during basic education. In Brazil, the implementation of courses that articulate statistical content with didactics is urgent, since many initial teacher education programs present syllabuses for the discipline of statistics also offered to other fields that do not attend the specific needs of teacher education (Costa \& Nacarato, 2011). In addition, the implementation of the National Common Curriculum Base-BNCC (2017) poses another challenge to mathematics teachers who teach statistics, as it presents new contents to be addressed such as the boxplot and emphasize the importance of project work (Giordano et al., 2019). Thus, it is necessary to develop investigations that allow to understand the potential that training for teachers who teach statistics offers when their activities are based on elements of teaching practice. It is also necessary to understand how teachers develop their knowledge in this type of teacher education process.

This article reports a teacher education process for mathematics teachers for the development of didactics knowledge concerning the teaching of statistics conducted in the West Zone of Rio de Janeiro, 
Brazil. Supported by the dimensions of didactics knowledge presented by Ponte (2012) and based on a case study with two beginning teachers who participated in the course, we aim to answer the following question: How do teachers develop statistical knowledge and knowledge of teaching practice in the teacher education process?

\section{THEORETICAL FRAMEWORK}

\section{Guidelines and Challenges for Teaching Statistics}

According to Weiland (2017), advances in society raise the need to propose a definition of statistical literacy that includes active learning for the production of statistics combined with changes in the context. Gould (2017) presents a definition of statistical literacy that includes the following basic ideas: understanding who collects the data, why and in what way it is collected; knowing the processes of analysis and interpretation of data from random and non-random samples; having the ability to create data representations to answer questions related to reality; understand how data can be stored; realize that the representations created in statistical software may vary. Weiland (2017) and Gould (2017) emphasize an approach in which students go beyond the role of mere statistics consumer and receive the responsibility to produce statistical knowledge. Thus, this work cannot be developed from tasks limited to the reproduction of calculations without context. According to Weiland (2016), this type of approach is still very present in the teaching of statistics, making it necessary to reflect on exploratory teaching of statistical concepts, where investigations assume an essential place.

Statistical investigations involve different activities: asking questions, collecting and analyzing data, and interpreting the results. According to Franklin et al. (2005), in the question formulation phase, one or more questions are elaborated, which will be answered with the data; in the collection phase, a plan is created so that the data is properly accessed; in the analysis phase, graphic and numerical methods are chosen to support the analysis; finally, in the interpretation of results phase, the analysis is related to the question initially asked. In this process, the contrast between mathematics and statistics must be considered, to highlight the omnipresence of variability throughout the investigative cycle. In GAISE II (Bargagliotti et al., 2020), the model depicted in Figure $\mathbf{1}$ is proposed for this investigative process.

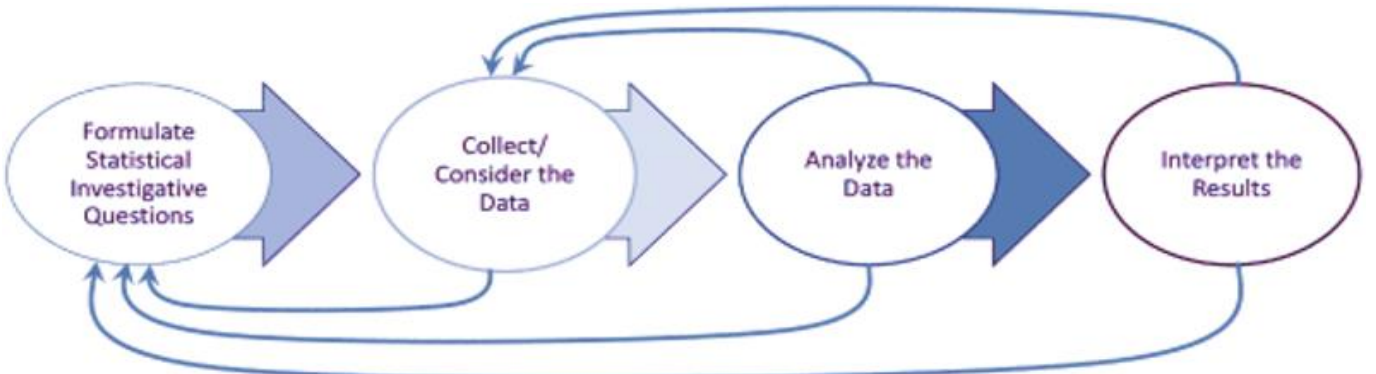

Figure 1. Statistical problem-solving process (adapted from Bargagliotti et al., 2020)

In the Brazilian context, the BNCC (2017) presents the investigative cycle underlying the proposal of work by projects. In this process, the desirable statistical knowledge to be developed by students in basic education referred to in GAISE II (Bargagliotti et al., 2020) are divided into three levels of development. Regarding learning about the mean, for example, in the first level, the student associates the concept "to the value of a fair share". At this same level, the median is perceived as the order value of the middle of the data. At an intermediate level, the mean is recognized as the "break-even point" of the data distribution. The document also emphasizes that the reasoning about distributions begins to be better explored through comparisons between two samples of quantitative variables. At the last level, it is possible to differentiate the mean of a population from the mean of a sample, constituting a phase in which the student is presented with the notion of sampling to make inferences about a given population. Furthermore, the formulation of questions for a statistical investigation can lead to multivariate analysis, where, later on, the communication of statistical reasoning involved in the investigative cycle takes a variety of formats-verbal, written, or visual. For Ben-Zvi (2000), the 
technological tools created to support the teaching and learning statistics allow the active construction of students' knowledge, providing opportunities to reflect on the observed phenomena and to develop metacognitive skills. Pratt et al. (2011) reinforce that, in some cases, the use of technology can further intensify the execution of works that do not consider the process but the final results. The authors claim that to avoid the misuse of technological resources in the school environment, the teacher must encourage communication and justification of conclusions by students.

\section{Didactics Knowledge Geared to Practice}

Different authors have studied the knowledge necessary for teaching. In a seminal article, Shulman (1986) points out the importance of linking pedagogical knowledge and content knowledge. His arguments have stimulated several analyses. Drawing on this idea, and searching for a dynamic model of knowledge associated with the educational practice of mathematics teachers, Ponte (2012) proposes a model that integrates different dimensions of didactics knowledge, seeking to avoid the segmentation among them (Figure 2). This model consists of the following dimensions: knowledge of teaching practice; knowledge of mathematics; knowledge of students and their learning; knowledge of the curriculum. As a model that prioritizes educational practice, this proposal has been integrated into different studies, including studies related to teachers' statistical knowledge (Quintas et al., 2015; Rodrigues \& Ponte, 2020).

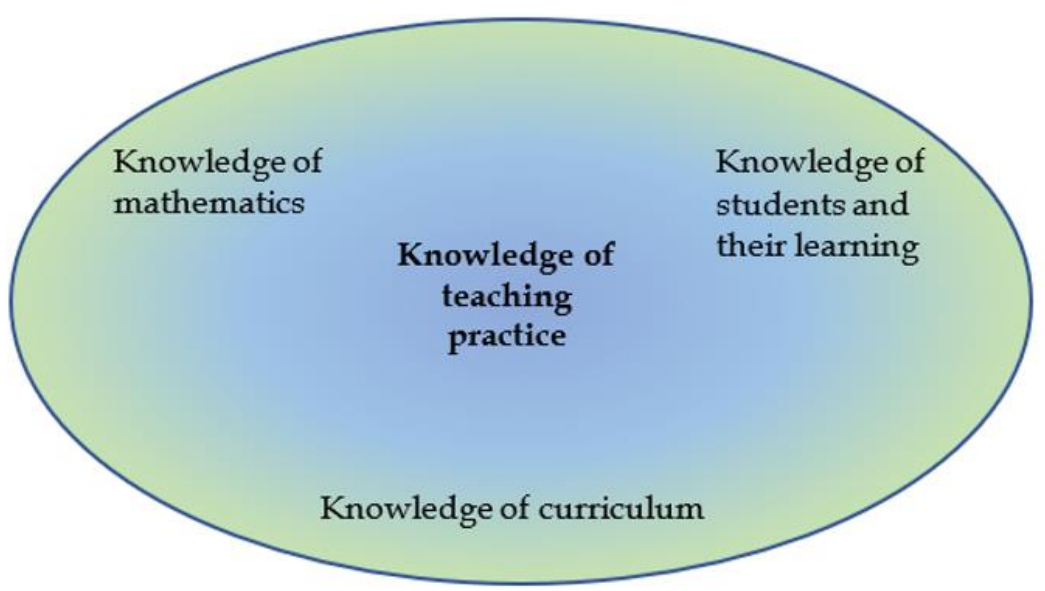

Figure 2. Dimensions of didactics knowledge (adapted from Ponte, 2012)

Regarding student knowledge, Ponte (2012) highlights that interests, reactions, values, and cultural references are considered beyond the learning and cognitive limitations of students. Thus, understanding the context in which students are inserted is crucial for the teaching-learning strategies adopted. Concerning knowledge of the curriculum, teachers must articulate the goals in the teaching of the contents, in addition to using and adapting teaching materials to different educational contexts.

Statistical knowledge refers to the fundamental concepts and procedures of the area, in addition to knowledge about school statistics. Thus, this dimension is not focused on the scientific knowledge of statistics, but on the teachers' perception of statistics, its application to problem-solving, as well as other aspects such as technology. The knowledge of teaching practice (or "instructional knowledge", as several authors say) refers to the ability to carry out the planning of each class, organize the performance of tasks and deal with the preparation, conduction, and evaluation of the teaching-learning process. In the context of teaching statistics, this knowledge is evidenced when the teacher manages to conduct educational tasks and experiences that involve central aspects, such as variability. Thus, the processes of planning, conducting, and evaluating a statistical investigation in the classroom can highlight this aspect of knowledge. Didactics knowledge is the part of professional knowledge called upon to intervene directly in teaching practice. Ponte (2012) refers that the knowledge of teaching practice is the "essential core" of didactics knowledge. Ponte et al. (2017) refer that practice can be characterized by two central elements: the task proposed to the students and the communication established in the 
classroom. Thus, the development of knowledge of teaching practice must be supported by reflection on these two elements.

According to Batanero and Díaz (2010), the statistical knowledge of teachers profoundly influences the way the discipline is taught and decisions regarding content approach strategies. Batanero et al. (2011) point out the various difficulties that teachers have regarding statistical concepts, highlighting the low understanding of measures of central tendency and measures of dispersion such as, for example, standard deviation - when presented in the form of a measure of sample homogeneity. Furthermore, such difficulties are accentuated in the comparison of distributions and the creation and interpretation of graphics. According to Stohl (2005), such mishaps are also evident in the implementation of teaching strategies, such as carrying out statistical investigations in the classroom; that is, this difficulty is related both to knowledge of statistics and of teaching practice.

\section{Teacher Education to Teach Statistics}

Teacher education is fraught with responsibilities, as promoting the development of statistical literacy is a major challenge. This fact has influenced different researches related to the continuing education of teachers, indicating that an exploratory approach to statistical tasks can support important learning for teachers (Estevam et al., 2018; Rodrigues \& Ponte, 2020). The exploratory tasks defined by Ponte (2005) prioritize whole class discussion and reflection. According to Franklin and Kader (2010), teachers must address problems that are relevant to the student's social context. The document Statistical Education of Teachers (Franklin et al., 2015), developed by the American Statistical Association (ASA), contains a series of recommendations for the education of statistics teachers. Among these guidelines, there is the need to provide teachers with moments of solving statistical problems included in the investigative cycle. Thus, these teachers must understand the statistical investigation process to assist their students, promoting the integration of appropriate technology to the established curriculum, to stimulate the development of statistical reasoning.

According to Barbosa et al. (2020), it is necessary to think about professional development processes that are capable of overcoming the technical rationality, which conducts teaching through a productivist conception, where teaching autonomy has no consistency (Contreras, 2002). For Smith (2001), practicecentered teacher education tends to prepare teachers with a more reflective, systematic, and uninterrupted stance on their actions as a teacher. Teacher education with these characteristics also enables the socialization of reflective practice with other educators who share the school environment. According to Oliveira and Serrazina (2002, p. 3), "the ability to reflect emerges when there is recognition of a problem, a dilemma and acceptance of uncertainty". Thus, the reflective posture must permeate the entire teaching process, to anticipate the students' difficulties and refine the different work proposals after each class. In this direction, Brown et al. (2018) emphasize the role of the teacher educator in this process, given that his/her own experiences help the teacher to reflect on their students' learning.

\section{STUDY CONTEXT AND METHODOLOGICAL ASPECTS}

\section{Teacher Education Course}

The course took place in 2018, with the participation of 18 mathematics teachers, during two modules of a specialization program for teachers from the West Zone, in Rio de Janeiro. The modules entitled Data Analysis I and II were part of a didactics set related to different themes present in mathematics of basic education. These two modules were developed over 10 sessions of 5 hours, divided into lessons of 50 minutes. This course is part of the second cycle of a Design Based Research, which went through a process of reflection and reformulation of the adopted design. The first cycle took place in 2017 at the same institution, with teachers with similar profiles. The structuring of the teacher education process was supported by guiding documents for the teaching of mathematics in Brazil (Brasil, 1997, 2017). Likewise, international documents such as the National Council of Teachers of Mathematics (Crosswhite et al., 1989) and the Guidelines for Assessment and Instruction in Statistics Education (GAISE) 
College Report (Franklin et al., 2005) were analyzed. The tasks developed during the sessions were characterized as exploratory (Ponte, 2005). In addition, we tried to develop activities associated with teaching practice, such as the analysis of videos on statistics, the analysis of student responses to the different tasks proposed, as well as the creation of lesson plans and subsequent execution (Smith, 2001). In this course, we sought to provide teachers with new experiences that would significantly reflect on their practices and that would integrate the context of work and the culture in which these professionals were inserted. It was also mobilized a safe environment for teachers to express their knowledge, concerns, and perceptions about the topic and its teaching. The activities carried out in the sessions are described in Table 1.

Table 1. Course sessions

\begin{tabular}{|c|c|}
\hline Sessions & Activities \\
\hline 1st session (5 hours class) & $\begin{array}{l}\text { Presentation of subject, clarifications on research carried out, and application of initial } \\
\text { questionnaire }\end{array}$ \\
\hline 2nd session (5 hours class) & Analysis of curriculum guidelines \& school materials \\
\hline 3rd session (5 hours class) & Introduction of fundamental concepts of statistics and analysis of a videotaped class \\
\hline 4th \& 5 th sessions (10 hours class) & Introduction to technological resources, with analysis \& solving of exploratory tasks \\
\hline 6th session (5 hours class) & $\begin{array}{l}\text { Analysis of written responses to different tasks of students in final years of elementary } \\
\text { school/Proposal for the elaboration of a lesson plan }\end{array}$ \\
\hline 7th session (5 hours class) & $\begin{array}{l}\text { Discussion about informal inferential reasoning from an example of statistical } \\
\text { investigation in classroom; presentation of fundamental concepts associated with } \\
\text { probabilistic distribution models }\end{array}$ \\
\hline 8th \& 9th sessions (10 hours class) & $\begin{array}{l}\text { Discussion about conducting statistical investigations \& carrying out an investigation with } \\
\text { teachers }\end{array}$ \\
\hline 10th session (5 hours class) & Final questionnaire \\
\hline
\end{tabular}

\section{Study Design}

The present study stems from the teacher education experience presented above, following a qualitative and interpretive approach based on a case study of two teachers. Based on empirical data, we intend to understand how teachers' knowledge develops. As our focus is to understand teachers' knowledge, taking into account the perspectives of the participants, we consider that the interpretive paradigm is adequate for this investigation. According to Amado (2017), the researcher who adopts the phenomenological-interpretive paradigm aims to demonstrate the particularities of the conclusions of the research, rather than obtaining generalizations. Thus, such conclusions assume a social representation allied to the theory, observing the process rather than just focusing on the product. According to Ponte (2006), a case study shows a situation endowed with specificities, where the researcher seeks to understand what is most characteristic, to enable a global understanding of a phenomenon.

\section{The Teachers}

The present work refers to the case study that involves two teachers-Tiago and Cláudio, both at the beginning of their careers and active participants in the course sessions. Given the interests shown by the teachers during the course and the constitution of similar profiles, interactions, perceptions and knowledge are objects of analysis. At the time of the course, Tiago and Cláudio were starting their careers as teachers. Both were 22 years old and completed a degree in mathematics in 2017. At the beginning of this course, Tiago was already working as a teacher in private schools in classes with a reduced number of students and easy access to technological resources. Cláudio's professional experience was limited to private lessons and classes taught under the Institutional Program for Teaching Initiation Scholarship (PIBID). While still doing his initial teacher education, Cláudio taught at a school in the West Zone of Rio de Janeiro, in larger classes and with little access to technological resources. Due to ethical issues, we use fictitious names for the teachers. 


\section{Data Collection and Analysis Procedures}

According to Amado (2017), a case study should focus on different sources of evidence. Thus, the collected data result from: (i) the initial and final questionnaires; (ii) teachers' responses to the proposed tasks; (iii) recordings of whole class discussions in the sessions; and (iv) interviews carried out after the course. The guide for these interviews can be found in Appendix A. Parts of the questionnaires (initial and final) in Appendix B and Appendix C, respectively. According to Magen-Nagar (2016, p. 520), "errors based teaching is focused on changing the misconceptions of a student significantly". Thus, to exemplify the proposal of the questionnaires, we selected questions that promote teachers' reflections based on authentic answers from students.

Through the questionnaires, it was noticed, initially, the knowledge of the teachers, as well as the knowledge they depicted after the course. Through written responses and recordings of discussions, data were obtained on the process of knowledge development of teachers. The recordings of the sessions were transcribed, and we initially searched for data related to the two teachers who constitute the cases of this investigation. Through the interviews, data related to the impact of the course on didactics knowledge were obtained -in particular, on statistical knowledge and knowledge of teaching practice. Initially, we carefully read the data collected. In addition to the interviews conducted after the course, we found a more active participation of the teachers who constitute the cases of this research in sessions $1,4,9$, and 10 .

We adapted the content analysis of the data obtained; with this type of approach, it is possible to represent rigorously and objectively the different data by coding and classifying it into categories and subcategories. Furthermore, through interpretive inferences inspired by the theoretical framework, it is possible to perceive the meaning attributed to the different elements analyzed (Amado, 2017). The categories were defined a priori, based on the adaptation of two dimensions of the teacher's didactics knowledge, described by Ponte (2012): statistical knowledge and knowledge of teaching practice (Table 2). Appendix D depicts framework for data analysis.

Table 2. Categories and subcategories

\begin{tabular}{ll}
\hline Categories & Subcategories \\
\hline Knowledge of statistical content & Statistical representations and measures \\
& The investigative cycle \\
Knowledge of teaching practice & Management of statistical tasks \\
& Conducting statistical investigations \\
\hline
\end{tabular}

The subcategories emerged from the articulation between a preliminary analysis of the data and studies on the knowledge of statistics and its teaching (Batanero et al., 2011; Franklin et al., 2015; Stohl, 2005).

\section{RESULTS}

Next, we present the results of different stages of the course, highlighting four episodes: initial knowledge; statistical task; statistical investigations; and reflections on learning. The episodes presented correspond to the chronology determined in the course. Tiago and Cláudio were part of the same group for whole class discussions at different times. When possible, we present their knowledge and reflections made at these collective occasions.

\section{Initial Knowledge}

The initial questionnaire enabled an understanding of the perceptions and knowledge that teachers initially had about statistics and its teaching. In this questionnaire, the teachers demonstrated misinterpretations of statistical concepts. We elucidate this situation from the teachers' responses to the task shown in Figure 3. 
A company has 300 employees. It is known that the average of their salaries is $R \$ 3000$, the mode is $R \$ 800$ and the median is $\mathrm{R} \$ 1200$.

a) In the context of the situation, interpret the meaning of: i) Mean; ii) Mode, and iii) Median.

b) Comment on the salaries of the company's employees.

Figure 3. Diagnostic questions

When answering the task, Cláudio talked about the average: "Sum of all salaries and divide by the number of employees in the company". He did not indicate the reasoning behind his answers; however, he explained the procedures carried out to obtain the measure. The same happens with the other measures, as the teacher described the way to know the median: "The salaries of each employee are organized in ascending or descending order, in this case, the salaries of the $15^{\text {th }}$ and $16^{\text {th }}$ employees are selected (which are those in the middle of this list) and then the two salaries are added up and divided by two". The lack of understanding regarding the application of measures, regarding the salaries, is present in point b), as the teacher chose to leave it blank. Regarding the mean, Tiago stated: "It would be the equal distribution of profit among employees". Concerning mode, the teacher explained: "The greatest number of employees receive $\mathrm{R} \$ 800.00$ ". About the median, the teacher presents an incomplete statement: "It is neither the highest nor the lowest salary". In a general assessment of the task, Tiago stated that "the greatest number of employees has a salary below the minimum wage". Despite trying to answer the question, the teacher did not present a reflection on the three measures articulated in the same context.

From the initial questionnaire, we analyze the teachers' knowledge concerning the teaching of statistics and the types of tasks they considered important. To illustrate the approach that he considers essential, Tiago referred to the work he usually develops with his students, mentioning tasks of "analyzing graphs and tables". Cláudio indicated the use of "exercises from books or handouts" as the main support in classes taught in the context professional internship and private tutoring. To lead teachers to express their perceptions about carrying out statistical investigations, one of the questions in the initial questionnaire included a situation of a statistical investigation carried out in elementary school. The question was on an activity developed by the teacher educator with a basic education class (Figure 4).

A $7^{\text {th }}$ grade class at a private school was researching the importance of healthy eating and decided to investigate the eating habits of the school's students. To carry out the investigation, the students elaborated questions related to the topic for their classmates to answer. However, they realized that it would be a lot of work to get all the students to answer the questions, as the school was composed of $67^{\text {th }}$ grade classes, $58^{\text {th }}$ grade classes, and $39^{\text {th }}$ grade classes, all of which consisted of 40 students. To solve this problem, a group of students established the following discussion: Marcelo: We can only collect responses from the $7^{\text {th }}$ grade, as we have more contact with them at school break. Camila: What about students from other grades? Will they not be represented?

Tamires: I think we can choose one class from each grade...

Figure 4. Reflection task on carrying out a statistical investigation with students

After a brief initial discussion that took place regarding statistical investigations, the teachers were invited to write about how they would proceed if they were teachers in this class, taking as a starting point the choice of the sample. In the description of his approach, Cláudio mentioned carrying out whole class discussions with students throughout the investigative cycle, allowing students to have an active role. Regarding the process of choosing the sample, the teacher referred to "discussing the size of the sample", highlighting the importance of representativeness. For Cláudio, it was essential to "reflect on whether the data will be quantitative and/or qualitative" and "to discuss the best way to represent data; either by tables, graphs or measurements". He also talked about the importance of a "critical analysis of the data" for the subsequent presentation of conclusions. Tiago presented a description in which there was little participation from students, using whole class discussions and students' reflections in a restricted way. The teacher also said that he would guide the students to "choose distinct groups, which would differ not only in age but also in eating habits"; however, he did not explain how this choice 
process would be conducted. The same happened for the data collection and analysis process; the teacher stated that he would "set up a questionnaire" and give it to the students "to organize it in column charts". Nonetheless, he did not refer to variable types or to possible statistical representations.

\section{Tasks}

During the course, exploratory statistical tasks applicable to different grades at basic education were presented to the teachers. The aim was to encourage discussions about doing this type of task in the school context, in addition to providing the development of teachers' statistical knowledge. In session 4, there were discussions about these activities. Tiago, initially, considered the inclusion of graph interpretation questions in assessments essential, for a more in-depth work later:

Tiago: I think the use of graphs helps. Well, it doesn't help in everything... For a complete and rich analysis, no (...) I usually put a graph in all the assessments (...) Then, I deepen the topic with a more complete class.

Teacher educator: But does this fuller class usually happen?

Tiago: So, I'll be honest with you... That is not always the case. However, I make the student at least have the contact (Tiago, session 4).

After the teacher educators' question, the teacher reflected that the inclusion of statistical questions in assessments is not enough to support students' learning and, consequently, does not support the development of students' statistical literacy. The teacher also admitted that the in-depth work, carried out later, is not consolidated in many cases. This moment of discussion contributed to the whole class reflection between Tiago and the other participants about the importance of an exploratory and detailed approach to statistics in basic education.

As mentioned above, different tasks were introduced so that participants could solve them. One of the tasks carried out by the teachers was to identify the responses of students from different types of representations and statistical measures (Figure 5). 


\begin{abstract}
Three municipal schools in the West Zone of Rio de Janeiro (A, B, and C) were selected. Each of the three schools had $47^{\text {th }}$ grade classes, totaling 100 students for this school year in each school. The grades obtained in a bimonthly mathematics test were registered. Regarding the data obtained, three teachers decided to compare the performance of students in the $7^{\text {th }}$ year of each school in mathematics. One teacher calculated some sample characteristics and two others used graphical representations.
\end{abstract}

Teacher I

\begin{tabular}{|cccc|}
\hline & School A & School B & School C \\
\hline Mean & 6.2 & 6.1222 & 5.5323 \\
\hline $\begin{array}{c}\text { Interquartile } \\
\text { range (IaR) }\end{array}$ & 4 & 6 & 3 \\
\hline $\begin{array}{c}\text { Standard } \\
\text { deviation }\end{array}$ & 2.4549 & 2.8938 & 2.2018 \\
\hline
\end{tabular}

Teacher II

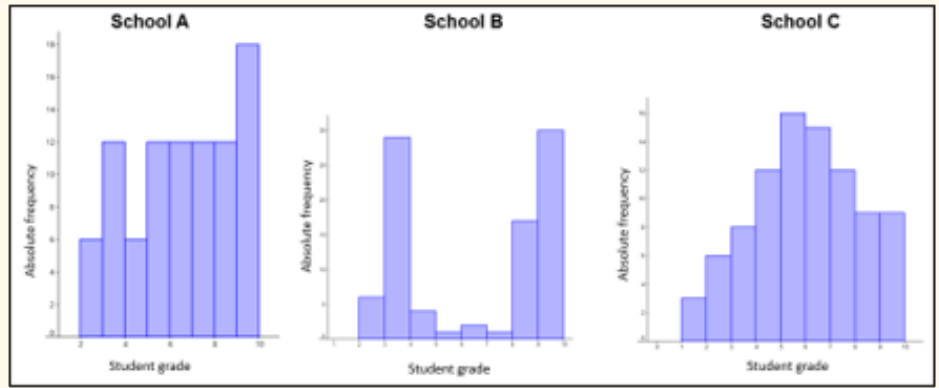

Teacher III

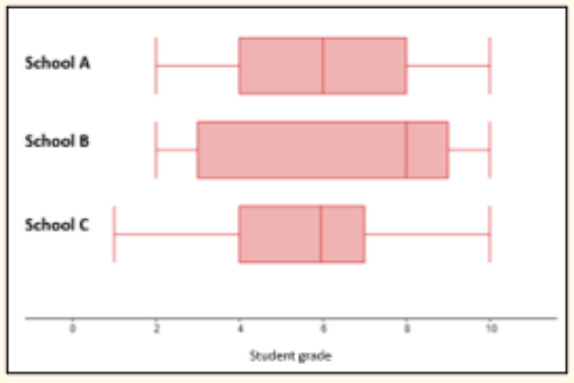

Figure 5. Task about measurements and graphs (adapted from Martins \& Ponte, 2011)

From the three presentations about the same situation, the teachers were invited to reflect on the most relevant aspects of the students' responses from the three schools. Different from the explanations found in the initial questionnaire, the teachers sought to make more consistent readings of the representations and measures presented in the task. This evolution is evident in the explanation given by Cláudio, who initially made a written analysis of the situation and then explained his interpretation to his colleagues:

I will say what I understand. Teacher 1 averaged the grades. He also puts the interquartile range and the standard deviation. I found this interesting because he is said that the mean does not represent the student who got a ten, for example (Cláudio, session 4).

Cláudio emphasized the need for other measures to understand the population behavior. The teacher interpreted the mean as a balance point, noting that, in some cases, the mean cannot be considered a representative measure of the data set. He continued his presentation, exploring other information present in the task, explaining that:

The standard deviation and range at school B are quite high, which indicates that grades vary a lot. However, I think you can observe more things when you analyze the graph. Many students got very good grades and many got very bad grades. Moreover, the graph shows that well. It also shows the variation... In class B, the 
variation is much greater. If we look at the graph made by teacher 2 for class $B$, we can even make a mistake. If you look in comparison to the mean, it deviates a lot. In teacher 3's graph, we can also see the variation (Cláudio, session 4).

Following Cláudio's explanations, it can be noticed the importance of integrating the different measures and representations into his interpretation. The teacher sought to highlight central aspects indicated in each case, such as the possibility of visualizing the variability of data from the histogram. He continued his observation on variability by analyzing the boxplots and density of each represented subset. The teacher also emphasized the importance of contrasting the standard deviation and interquartile range with the average of the grades for better interpretation.

\section{Statistical Investigations}

In the $8^{\text {th }}$ and $9^{\text {th }}$ sessions, it was proposed to teachers to carry out a statistical investigation. Due to logistical factors, the investigation was based only on data from the participating teachers. During the investigation, the teachers were able to use Geogebra and Excel. The teachers were divided into trios or pairs and, inspired by the statistical research presented by Sousa (2002), they formulated research questions related to their characteristics, habits, and routines. One of the questions elaborated by Tiago and Cláudio's group was "Does the group do more physical activities than they study weekly?" To answer the question, Cláudio and Thiago collected data on the hours that all participants dedicated weekly to the activities described. They stressed that the objective was to compare the hours spent by teachers on activities other than work. Thus, they collected data related to time spent on physical activities and time spent studying in addition to time related to their class plans (language studies, courses, etc.) through a virtual form.

Cláudio and Tiago showed interest in presenting discussions about this issue to other colleagues because they articulated two variables. They decided to present data through boxplots, as they had a limited number of data for each variable. They reported that boxplots facilitate the comparison between medians, quartiles, maximum and minimum values, and detection of outliers. For the teachers, the observation of central tendency values and symmetry of the grouped data was essential to analyze the data concerning the question. For this representation, the teachers opted for Geogebra, which constitutes a dynamic environment for the simultaneous analysis of more than one variable. Thus, in the presentation of the report, as well as in the whole class discussion with other colleagues, Cláudio and Tiago presented boxplots built-in Geogebra to support the discussion, in addition to measures of central tendency and dispersion related to the data (Figure 6).

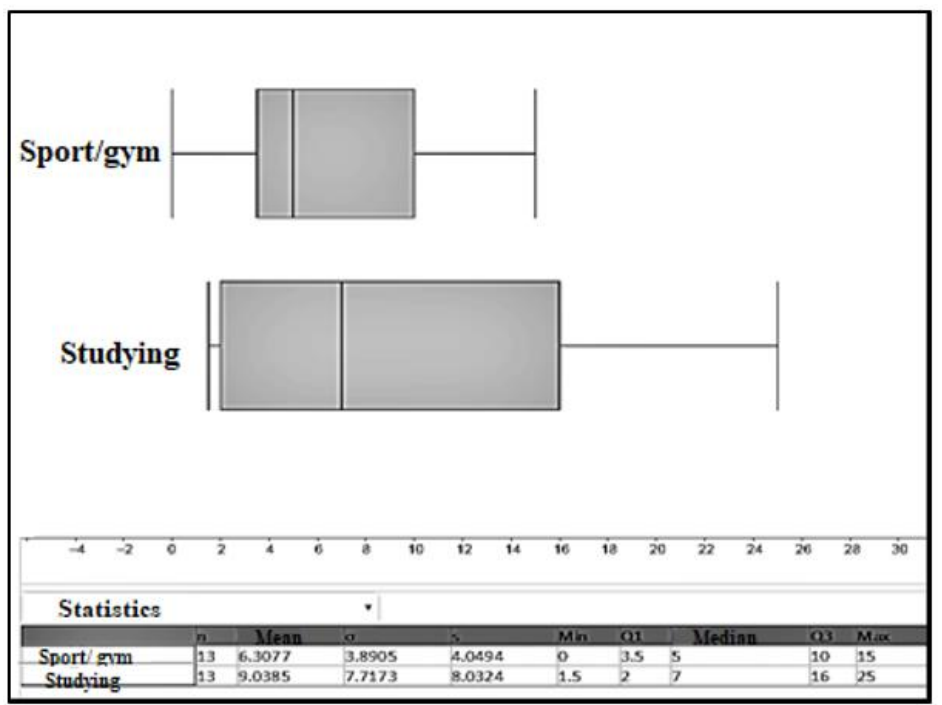

Figure 6. Boxplots built by the teachers 
In the report made by Cláudio and Tiago, it was possible to observe that the teachers recognized the potential of the selected chart:

\begin{abstract}
Regarding "Studying", we observed that approximately $25 \%$ of the class studies more than they do physical activities. We also noticed that there is a person in the class who does not do physical activities. $75 \%$ of the highest values in the physical activity graph range within $50 \%$ close to the median of the "studying" graph (Investigation report).
\end{abstract}

In presenting the results to the class, Cláudio explained that they decided to put the measures of dispersion in the report to focus on the variability of the data: "On average, the class studies more than they do physical activity (...). The data varies a lot." After a whole class discussion of the results, the teachers were able to reflect on relevant topics such as healthy habits and other social issues related to the investigation carried out. The importance of the context in the teaching of statistics was reinforced at different moments of the course. In the final questionnaire, a reflection on carrying out a statistical investigation based on the report of a teaching experience carried out by the teacher educator in basic education was proposed. In this report, the role of the context inherent in statistical investigations was highlighted, as the students themselves decided to investigate issues that caused them discomforts, such as bullying and racism (Figure 7).

Imagine that you, a mathematics teacher in an $8^{\text {th }}$-grade class at a certain school, have proposed a statistical investigation to be carried out in the classroom.

Suppose that the students involved have shown an interest in asking questions related to bullying those students at the school face, regarding the standards of beauty imposed by society and skin colors. The school in question is made up of classes from $6^{\text {th }}$ to $9^{\text {th }}$ grade, totalling 1000 students. Among the questions that the students asked are:

- When bullying is related to body shape, do younger students suffer more than older ones?

- Do girls suffer more racism than boys?

- Concerning facial features (nose and mouth shape), do blacks suffer more bullying?

Figure 7. Reflection task on carrying out a statistical investigation with students

Similar to the proposal contained in the initial questionnaire, this situation was presented so that the teachers could report how they would conduct the statistical investigation with their classes, from the perspective of the different stages of the investigative cycle. In the answers produced by the teachers, there were references to the mobilization of discussions on the use of a census or sample, as is evident in Cláudio's writing:

We would discuss whether the investigation will be with the entire population or if we will use a sample, we would reflect on whether the variables would be qualitative or quantitative, how we would represent the results, what the questions would be, whether respondents would have limited answers or not (Cláudio, report).

Cláudio also demonstrated the importance of efficiently conducting the process of collecting data from his students, given that the chosen topics are highly complex. The teacher stated that he would lead the discussions on the topic based on the motivations that the students had to formulate each question. The professor mentioned that, in this case, he would seek to relate these motivations to the final results so that the context could be valued in the investigation. The teacher stated: "We would comment on which factors contributed to the creation of questions to be analyzed, which information contributed to the formulation of hypotheses and the possible results" (Cláudio, report).

Tiago talked about the active role of the student in this process, highlighting the importance of raising whole class discussions at all stages of the investigation. Although the teacher did not specifically refer to his actions as a teacher in conducting reflections on the topic beyond statistical processes, he indicated 
that the "discovery" of different results through an activity developed by the students themselves enhances the development of statistical literacy. The teacher also showed the importance of highlighting the students' prior knowledge, essentially about statistical concepts. Tiago also stated: "I would suggest the use of excel or GeoGebra, to build graphs and tables" (Tiago, report).

\section{Reflections on Learning}

After concluding the sessions, semi-structured interviews were conducted with Tiago and Cláudio, so that we could understand how they assessed their learning in the course. In this process of reflection after the course, the teachers talked about the experiences they had in their initial teacher education. Cláudio mentioned the lack of articulation between content and didactics to teach the contents:

Until then, we didn't have much idea of how many things involved data processing (...) There's a lot of content to learn during the undergraduate course and rarely had time to discuss teaching and learning in each subject (Cláudio, interview).

Tiago reported the absence of the study of some statistical concepts in the initial teacher education, as quartiles and boxplots. The teacher valued carrying out a statistical investigation in the course, as he had not previously experienced it:

During my undergraduate course (initial teacher education), I had not seen this part of quartiles, boxplots (...) I had never collected data and now I had an application to collect data, how to do, how to conduct research work, I had never seen this during my undergraduate course (Tiago, interview).

The teachers also reported that prior knowledge about the use of technology associated with exploratory data analysis was quite limited. However, based on their teacher education experience, they began to consider that the use of technological resources in statistical investigations was essential:

I had never used Geogebra. Just once, in a Calculus III class... The technological resources were a differentiating factor, besides having done an investigation in the room. See together how the data is handled... (Cláudio, interview).

Showing in the laboratory how it works, how those data are, collecting that data, and creating something very practical, brought a much more comprehensive learning than the entire period (during the undergraduate course) (Tiago, interview).

In the interview, Tiago emphasized the importance of introducing exploratory data analysis using technology, without ignoring that this is a complex job, stating that "technology alone does not solve everything" (Tiago, interview). The teacher realized that this work depends on the teacher's fundamental role in mediating the teaching-learning process and exploring data dynamically. Recognizing the initial difficulties with statistical concepts and the technology associated with their teaching, the teachers referred to the learning gained in the course, relating them to professional practice. Still, regarding carrying out of statistical investigations and the use of technology, Tiago explained:

Currently, I'm at a school that is super technological and it demands a lot from me (...). For example, I'm already scheduling field research [statistical investigation] with students (...). What a wonderful thing! Sometimes I do a trip when I'm in a classroom (Tiago, interview).

Tiago said that the experiences he had in the course made him reflect on his practice as a teacher. In addition, he emphasized that, despite having a work environment conducive to carrying out 
exploratory activities associated with technology, he did not have enough knowledge to hold this type of teaching.

\section{DISCUSSION}

This study shows the activity carried out at different moments of a course on statistics and statistics teaching. It also highlights the development of the participants' didactics knowledge, specifically concerning statistical knowledge and knowledge of teaching practice. Concerning statistical knowledge, the teachers initially demonstrated limitations in their knowledge of the content. In the initial questionnaire, Cláudio presented descriptions for carrying out statistics calculations but did not indicate their meanings according to the context. Tiago sought an articulation between the statistics measures and the context, but he presented limited perceptions that are similar to those of a student at an elementary level, as in defining the average as an "equal part" (Bargagliotti et al., 2020). Other limitations on teachers' statistical knowledge are noticeable in the initial description of a statistical investigation in the school context, where they demonstrated little understanding of sampling and data collection processes for certain variables. The lack of understanding of these concepts was noticeable in the way they described their actions to carry out a statistical investigation with their students (Batanero \& Díaz, 2010; Stohl, 2005). In the course, the teachers learned several statistical concepts and their articulations in the investigation context. They were able to articulate statistical concepts to the contexts addressed in the tasks, showing a more advanced understanding of measures of central tendency. This advance is evident in carrying out a statistical investigation, where the teachers sought to formulate multivariate statistical questions and reasoned about distributions for comparing two groups (Bargagliotti et al., 2020).

In the beginning of the course, the technical rationality described by Contreras (2002) was notorious in the teachers' descriptions of their lessons and in the way they demonstrated their knowledge of teaching practice. Cláudio said he carried out a work limited to the exercises proposed in handouts and books used at school. Tiago mentioned exercises for interpreting tables and graphs, which do not encourage an active engagement of students in the production of statistics (Weiland, 2016). The teachers also showed that they did not know the investigative cycle as a school activity, as they did not experience such activities in their initial teacher education. In whole class discussions on the exploratory approach to statistics, the teachers were able to reflect on a new teaching perspective, beyond proposing doing calculations with no context. They began to value the active role of students in carrying out statistical investigations. Thus, the activities carried out in the course made the teachers to reflect on their practices. Social issues had less relevance in their descriptions; however, these perceptions may tend to improve in practice. They also highlighted the need to include technological resources in their classes for the active construction of students' knowledge (Ben-Zvi, 2000).

\section{CONCLUSIONS}

This study contributes to research on the initial and continuing education of the mathematics teacher who teaches statistics. The study shows that the exploratory approach of statistics, associated with the articulation between the statistical content and its didactics adopted in the course, provided the development of knowledge of teachers concerning knowledge of the content and their teaching practice. The choice of the case study of two teachers enabled a detailed analysis of the different moments of the course, so that the evolution of their learning was noticeable. This study provides evidence that teacher education activities that promote strong dialogue between theory and practice can prepare teachers effectively for teaching statistics linked to contexts. We recommend conducting courses that allow longer statistical activities to be carried out, including more sophisticated data analyses.

Author contributions: All authors were involved in concept, design, collection of data, interpretation, writing, and critically revising the article. All authors approve final version of the article.

Funding: The research reported in this paper was supported by FCT - Fundação para a Ciência e a Tecnologia through the grant 2020.07528.BD granted to the first author. 
Declaration of interest: Authors declare no competing interest.

Data availability: Data generated or analysed during this study are available from the authors on request.

\section{REFERENCES}

Aikenhead, G. S. (1996). Science education: Border crossing into the subculture of science. Studies in Science Education, 27(1), 1-52. https://doi.org/10.1080/03057269608560077

Amado, J. (2017). Manual de investigação qualitativa em educação [Qualitative research handbook in education]. Imprensa da Universidade de Coimbra [University of Coimbra Press]. https://doi.org/10.14195/978-989-26-1390-1

Barbosa, G. C., Santos, S. S., Tinti, D. S., \& Lopes, C. E. (2020). Análise de trajetórias de professores que ensinam probabilidade e estatística com auxílio do software IRAMUTEQ [Trajectory analysis of teachers who teach probability and statistics with the help of IRAMUTEQ software]. Jornal Internacional de Estudos em Educação Matemática [International Journal of Studies in Mathematics Education], 13(4), 420-428. https://doi.org/10.17921/2176-5634.2020v13n4p420-428

Bargagliotti, A., Franklin, C., Arnold, P., Gould, R., Johnson, S., Perez, L., \& Spangler, D. (2020). Pre-K-12 guidelines for assessment and instruction in statistics education (GAISE) report II. American Statistical Association and National Council of Teachers of Mathematics. https://www.amstat.org/asa/files/pdfs/GAISE/GAISEIIPreK-12_Full.pdf

Batanero, C., \& Díaz, C. (2010). Training teachers to teach statistics: What can we learn from research? Statistique et Enseignement [Statistics and Education], 1(1), 5-20.

Batanero, C., Burrill, G., \& Reading, C. (2011). Overview: Challenges for teaching statistics in school mathematics and preparing mathematics teachers. In C. Batanero, G. Burrill, \& C. Reading (Eds.), Teaching statistics in school mathematics: Challenges for teaching and teacher education (A joint ICMI/IASE study) (pp. 407-418). Springer. https://doi.org/10.1007/978-94-007-1131-0

Ben-Zvi, D. (2000). Toward understanding the role of technological tools in statistical learning. Mathematical Thinking and Learning, 2(1 \& 2), 127-155. https://doi.org/10.1207/S15327833MTL0202_6

Borges, S. P., \& de Carvalho, E. T. (2020). The role of the trainer in the continuing education process: Trainers or informants. Research, Society and Development, 9(3), 1-18. https://doi.org/10.33448/rsd-v9i7.3787

Brasil. (1997). Parâmetros curriculares nacionais: Matemática (Ensino fundamental) [National curriculum parameters: Mathematics (Elementary school).]. Brasília: Ministério da Educação. Secretaria de Educação Fundamental [Brasilia: Ministry of Education. Secretary of Elementary Education].

Brasil. (2017). Base Nacional Comum Curricular-Educação é a Base: Ensino Fundamental [National Curricular Common BaseEducation is the Base: Elementary School]. Ministério da Educação [Ministry of Education].

Brown, L., Helliwell, T., \& Coles, A. (2018). Working as mathematics teacher educators at the metalevel (to the focus of the teachers on developing their teaching). Spanish Society for Research in Mathematics Education, 13, 105-122. https://doi.org/10.35763/ aiem.v0i13.230

Clarke, D. (2000). Time to reflect. Journal of Mathematics Teacher Education, 3(3), 201-203. https://doi.org/10.1023/A:1017398025800

Contreras, J. (2002). A autonomia de professores [The autonomy of teachers]. Cortez.

Costa, A., \& Nacarato, A. (2011). A estocástica na formação do professor de matemática: Percepções de professores e de formadores [Stochastics in mathematics teacher education: Perceptions of teachers and trainers]. Bolema, 24(39), 367-386.

Crosswhite, F. J., Dossey, J. A., \& Frye, S. M. (1989). NCTM standards for school mathematics: Visions for implementation. Journal for Research in Mathematics Education, 20(5), 513-522. https://doi.org/10.2307/749425

Etevam, E. J. G., Cyrino, M. C., \& Oliveira, H. (2018). Desenvolvimento do conhecimento estatístico para ensinar a partir da análise de tarefas em uma comunidade de professores de matemática [Development of statistical knowledge to teach from task analysis in a community of mathematics teachers]. Revista de Ensino de Ciências e Matemática [Journal of Science and Mathematics Teaching], 9(2), 32-51. https://doi.org/10.26843/rencima.v9i2.1643

Franklin, C., \& Kader, G. (2010). Models of teacher preparation designed around the GAISE framework. In C. Reading (Ed.), Proceedings of the $8^{\text {th }}$ International Conference on Teaching Statistics. International Association for Statistics Education, Ljubljana (Slovenia).

Franklin, C., Bargagliotti, A., Case, C., Kader, G., Scheaffer, R., \& Spangler, D. A. (2015). The statistical education of teachers. American Statistical Association.

Franklin, C., Kader, G., Mewborn, D., Moreno, J., Peck, R., Perry, M., Scheaffer, R. (2005). Guidelines for assessment and instruction in statistics education (GAISE) report. American Statistical Association.

Garfield, J., \& Ben-Zvi, D. (2008). Developing students' statistical reasoning: Connecting research and teaching practice. Springer.

Giordano, C. C., Araújo, J. R. A., \& Coutinho, S. Q. S. (2019). Educação estatística e a base nacional comum curricular: O incentivo aos projetos [Statistical education and the common national curriculum base: Incentive to projects]. Revista Eletrônica de Educação Matemática [Electronic Magazine of Mathematics Education], 14, 1-20. https://doi.org/10.5007/1981-1322.2019.e62727

Gould, R. (2017). Data literacy is statistical literacy. Statistics Education Research Journal, 16, 22-25. https://doi.org/10.52041/ serj.v16i1.209

Magen-Nagar, N. (2016). Examining teaching based on errors in mathematics amongst pupils with learning disabilities. European Journal of Science and Mathematics Education, 4(4), 506-522. https://doi.org/10.30935/scimath/9490 
Oliveira, A. L., \& Serrazina, L. (2002). A reflexão e o professor como investigador [Reflection and the teacher as researcher]. In GTI (Ed.), Reflectir e investigar sobre a prática profissional [Reflect and investigate professional practice]. APM.

Ponte, J. P. (2011). Preparing teachers to meet the challenges of statistics education. In C. Batanero, G. Burrill, \& C. Reading (Eds.), Teaching statistics in school mathematics: Challenges for teaching and teacher education (A joint ICMI/IASE study) (pp. 299-309). Springer. https://doi.org/10.1007/978-94-007-1131-0_29

Ponte, J. P. (2012). Estudiando el conocimiento y el desarrollo profesional del profesorado de matemáticas [Studying the knowledge and professional development of mathematics teachers]. In N. Planas (Ed.), Teoría, crítica y práctica de la educación matemática [Theory, criticism and practice of mathematics education] (pp. 83-98). Graó.

Ponte, J. P., Mata-Pereira, J., Quaresma, M., \& Velez, I. (2017). Formação de professores dos primeiros anos em articulação com o contexto de prática de ensino de matemática [Early years teacher training in conjunction with the context of mathematics teaching practice]. Revista Latinoamericana de Investigación en Matemática Educativa [Latin American Journal of Research in Educational Mathematics], 20(1), 71-94. https://doi.org/10.12802/relime.17.2013

Pratt, D., Davies, N., \& Connor, D. (2011). The role of technology in teaching and learning statistics. In C. Batanero, G. Burrill, \& C. Reading (Eds.), Teaching statistics in school mathematics: Challenges for teaching and teacher education (A joint ICMI/IASE study) (pp. 97-107). Springer. https://doi.org/10.1007/978-94-007-1131-0_13

Quintas, S., Ferreira, R., \& Oliveira, H. (2015). O conhecimento didático de estatística de duas professoras de matemática sobre dados bivariados [The didactic knowledge of statistics of two mathematics teachers on bivariate data]. Bolema, 29(51), 284306. https://doi.org/10.1590/1980-4415v29n51a15

Rodrigues, B. M. B., \& Ponte, J. P. (2020). Desenvolvimento do conhecimento didático de professores em estatística: Uma experiência formativa [Development of teachers' didactic knowledge in statistics: A formative experience]. Zetetike [Zetics], 28, 1-20. https://doi.org/10.20396/zet.v28i0.8656882

Sander, G., \& Klein, F. (1987). Technology in a non-traditional learning environment. Learning in Higher Education, 4(1), $92-98$.

Shulman, L. (1986). Those who understand: Knowledge growth on teaching. Educational Researcher, 15(2), 4-14. https://doi.org/ 10.3102/0013189X015002004

Smith, M. S. (2001). Practice-based professional development for teachers of mathematics. NCTM.

Sousa, O. (2002). Investigações estatísticas no $6^{\circ}$ ano [Statistical investigations in the 6 th grade]. In GTI (Ed.), Reflectir e investigar sobre a prática profissional [Reflect and investigate professional practice] (pp. 75-97). APM.

Stohl, H. (2005). Probability in teacher education and development. In G. Jones (Ed.), Exploring probability in schools: Challenges for teaching and learning (pp. 345-366). Springer. https://doi.org/10.1007/0-387-24530-8_15

Weiland, T. (2016). The importance of context in task selection. Teaching Statistics, 39(1), 20-25. https://doi.org/10.1111/test.12116

Weiland, T. (2017). Problematizing statistical literacy: An intersection of critical and statistical literacies. Educational Studies in Mathematics, 96(1), 33-47. https://doi.org/10.1007/s10649-017-9764-5 


\title{
APPENDIX A
}

\section{Guide for the Interview}

\author{
Teacher's background \\ i) What reasons led you to become a mathematics teacher? \\ ii) What are the main traits that characterize you as a mathematics teacher? \\ iii) Related to the work you develop as a teacher, which aspects give you greater or lesser pleasure? \\ iv) What motivated you to participate in this postgraduate course? \\ v) What were your expectations when participating in this experience? Have they been fulfilled?
}

\section{Work developed in class}

i) Could you describe the work carried in the classes of the postgraduate course modules?

ii) Considering all the learning situations you experienced during this period, which one marked you most significantly?

iii) What are the most important learning experiences that you consider to have accomplished or what knowledge did you consolidate during these two modules? Do this learning make you to reflect on your teaching practice?

Prospects on the teaching and learning of statistics

i) What are the concepts that you consider essential to work with your elementary education students for the development of statistical literacy?

ii) To promote your students' learning, do you think you can use tasks similar to those used throughout this course or do you think they should be different tasks? Why?

iii) From your point of view, what characteristics should the tasks proposed to students have? (should they be homogeneous or diversified?)

iv) What learning objectives can be achieved with the work related to: a) statistical representations and measures; b) use of technology; and c) conducting statistical investigations?

v) What teacher knowledge do you consider essential to develop this work in the classroom? 


\section{APPENDIX B}

\section{One Question from the Initial Questionnaire}

A task imolving two types of graphs is presented below.

A) Solve the proposed task justifying your reasoning

1) In a class, an interview was conducted to find out which pizza students liked the most. See the following graphs:

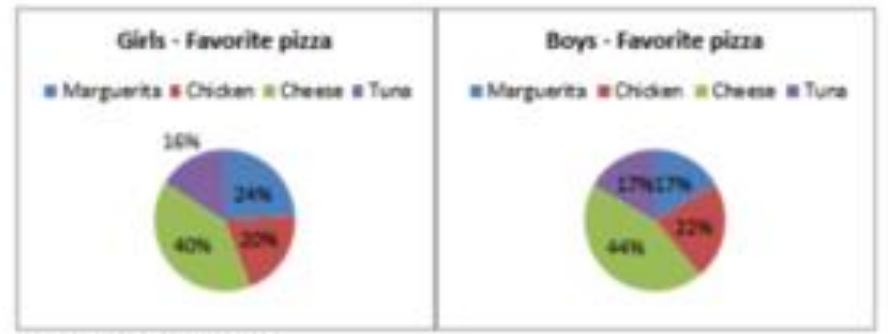

Answer $\mathrm{T}$ for true and $\mathrm{F}$ for false statements.

a) the number of boys preferring cheese pizza is highex than the number of girls who have a preference

for this flavor.

b) the number of girls who like tuna pizza is more than number of boys who have a preference for this flavor.

c) the number of boys preferring chicken pizza is higher than the number of girls who prefer this flavor. Explain your reasoning to find these answers.

II) Now, look at another representation of the situation describod earlier.

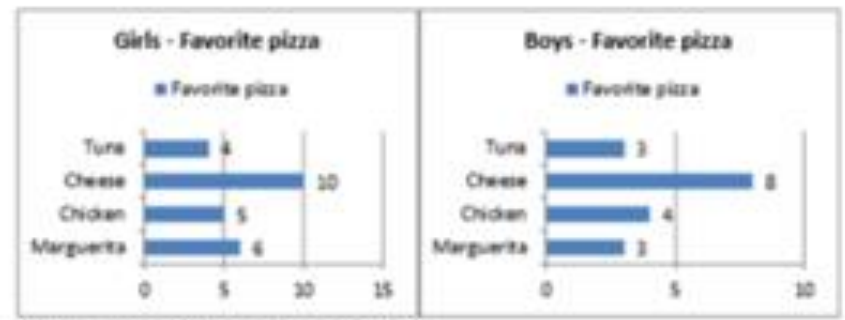

Do the conclusions remain the same? If not, please justify.

(Source: task adapted from Martins and Ponte, 2011)

B) The task was proposed to a group of students in the ninth grade of Elementary School A student who solved the task answered ' $\mathrm{T}$ ' for the statements in part $\mathrm{D}$ ) of the task, explaining that he used "the comparison between the graphs" to reach his conclusions. However, when viewing the graphs presented in part III), the student gave the following answer:

Do the conclusions remain the same? If not, please justify.

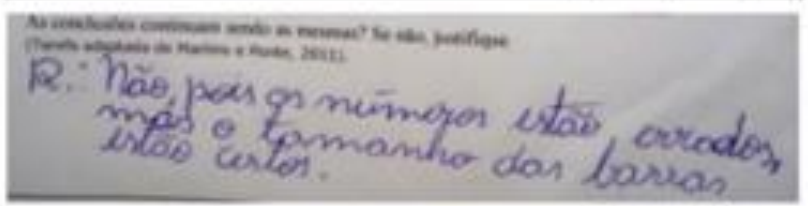

Answer: No, because the numbers are wrong but the size of the bas is correct.

How would you evaluate the student's answer? Please justify. 


\section{APPENDIX C}

\section{One Question from the Final Questionnaire}

A teacher presented to her students a task whose purpose was to make them realize the applicability of the line graph, as seen below.

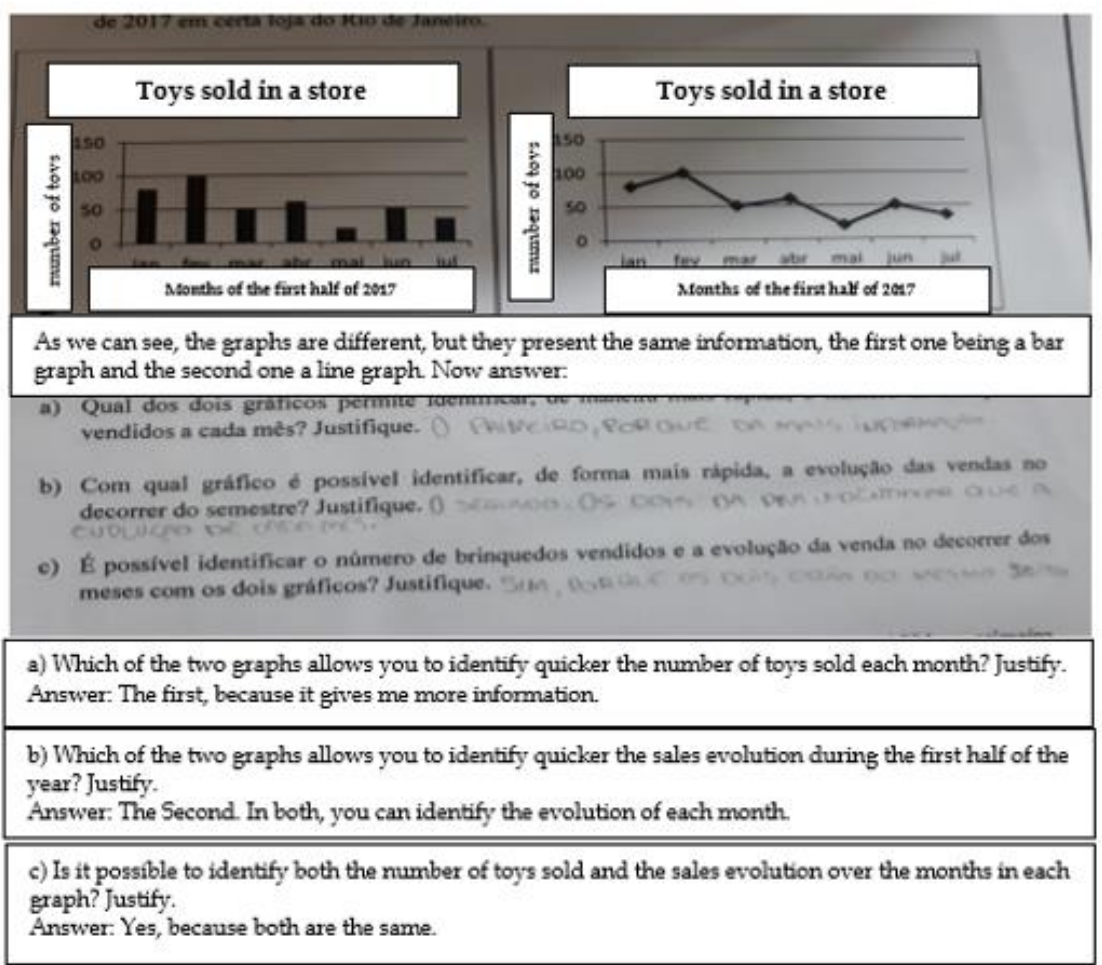

When observing the student's response to item c ("Yes, because both are the same"), answer:

a) What can you, teacher, say about the understanding that the student demonstrates about graphic representations?

b) How would you help him to build his knowledge about this type of graph? 


\section{APPENDIX D}

Framework for Data Analysis

\begin{tabular}{|c|c|c|c|}
\hline Categories & Subcategories & Indicators & Registration units \\
\hline \multirow{5}{*}{$\begin{array}{c}\text { Knowledge of } \\
\text { statistical content }\end{array}$} & \multirow{3}{*}{$\begin{array}{l}\text { Statistical representations } \\
\text { and measures }\end{array}$} & Calculation without meaning & $\begin{array}{l}\text { Sum of all salaries and divide by the number of employees in the company... The salaries } \\
\text { of each employee are organized in ascending or descending order, in this case, the salaries } \\
\text { of the } 15 \text { th and } 16 \text { th employees are selected (which are those in the middle of this list) and } \\
\text { then the two salaries are added up and divided by two. (Claudio, initial questionnaire, } \\
\text { session 1) }\end{array}$ \\
\hline & & Misinterpretation & $\begin{array}{l}\text { It would be the equal distribution of profit among employees...The greatest number of } \\
\text { employees receive RS } 800.00 \text {... It is neither the highest nor the lowest salary...the greatest } \\
\text { number of employees has a salary below the minimum wage. (Tiago, initial questionnaire, } \\
\text { session 1) }\end{array}$ \\
\hline & & $\begin{array}{l}\text { knowledge of concepts } \\
\text { articulated to the context }\end{array}$ & $\begin{array}{l}\text { The standard deviation and range at school B are quite high, which indicates that grades } \\
\text { vary a lot. However, I think you can observe more things when you analyze the graph. } \\
\text { Many students got very good grades and many got very bad grades. Moreover, the graph } \\
\text { shows that well. It also shows the variation... In class B, the variation is much greater. If we } \\
\text { look at the graph made by teacher } 2 \text { for class B, we can even make a mistake. If you look in } \\
\text { comparison to the mean, it deviates a lot. In teacher 3's graph, we can also see the variation. } \\
\text { (Claudio, session 4) }\end{array}$ \\
\hline & \multirow[t]{2}{*}{ The investigative cycle } & $\begin{array}{l}\text { Use of technological resources for } \\
\text { the interpretation of results }\end{array}$ & $\begin{array}{l}\text { Regarding "Studying", we observed that approximately } 25 \% \text { of the class studies more than } \\
\text { they do physical activities. We also noticed that there is a person in the class who does not } \\
\text { do physical activities. } 75 \% \text { of the highest values in the physical activity graph range within } \\
50 \% \text { close to the median of the "studying" graph. (Investigation report) }\end{array}$ \\
\hline & & Relations between two variables & Does the group do more physical activities than they study weekly? (Investigation report) \\
\hline \multirow[t]{5}{*}{$\begin{array}{l}\text { Knowledge of } \\
\text { teaching practice }\end{array}$} & \multirow[t]{3}{*}{$\begin{array}{l}\text { Management of statistical } \\
\text { tasks }\end{array}$} & $\begin{array}{l}\text { Teaching perspective limited to } \\
\text { reading graphs extracted from } \\
\text { school textbooks }\end{array}$ & $\begin{array}{l}\text { Analyzing graphs and tables. (Tlago, initial questionnaire, session 1) } \\
\text { I think the use of graphs helps. Well, it doesn't help in everything... For a complete and rich } \\
\text { analysis, no (...) I usually put a graph in all the assessments (....) Then, I deepen the topic } \\
\text { with a more complete class. (Tiago, session 4) }\end{array}$ \\
\hline & & $\begin{array}{l}\text { Teaching perspective limited to } \\
\text { textbook use }\end{array}$ & Exercises from books or handouts. (Cláudio, initial questionnaire, session 1) \\
\hline & & Reflective position & $\begin{array}{l}\text { So, I'll be honest with you... That is not always the case. However, I make the student at } \\
\text { least have the contact. (Tiago, session } 4 \text { ) }\end{array}$ \\
\hline & \multirow[t]{2}{*}{$\begin{array}{l}\text { Conducting statistical } \\
\text { investigations }\end{array}$} & $\begin{array}{l}\text { Limited understanding of the } \\
\text { investigative cycle }\end{array}$ & $\begin{array}{l}\text { choose distinct groups, which would differ not only in age but also in eating habits...Set up } \\
\text { a questionnaire... To organize it in column charts. (Tiago, initial questionnaire, session 1) }\end{array}$ \\
\hline & & $\begin{array}{l}\text { Valuing teaching with } \\
\text { technological resources }\end{array}$ & $\begin{array}{l}\text { I had never used Geogebra. Just once, in a Calculus III class... The technological resources } \\
\text { were a differentiating factor, besides having done an investigation in the room. See together } \\
\text { how the data is handled... (Claudio, interview) } \\
\text { Showing in the laboratory how it works, how those data are, collecting that data, and } \\
\text { creating something very practical, brought a much more comprehensive learning than the } \\
\text { entire period (during the undergraduate course). (Tiago, interview) }\end{array}$ \\
\hline
\end{tabular}

